\title{
Lactic Acid Bacteria Strains Exert Immunostimulatory Effect on H. pylori-Induced Dendritic Cells
}

\author{
Małgorzata Wiese, ${ }^{1}$ Andrzej Eljaszewicz, ${ }^{1,2}$ Anna Helmin-Basa, \\ Marek Andryszczyk, ${ }^{3}$ Ilona Motyl, ${ }^{4}$ Jolanta Wieczyńska, ${ }^{5}$ Lidia Gackowska, ${ }^{1}$ \\ Izabela Kubiszewska, ${ }^{1}$ Milena Januszewska, ${ }^{1}$ and Jacek Michałkiewicz ${ }^{5}$ \\ ${ }^{1}$ Collegium Medicum, Nicolaus Copernicus University, M. Sklodowskiej-Curie 9 Street, 85-094 Bydgoszcz, Poland \\ ${ }^{2}$ Department of Regenerative Medicine and Immune Regulation, Medical University of Bialystok, Waszyngtona 13 Street, \\ 15-269 Bialystok, Poland \\ ${ }^{3}$ Faculty of Mechanical Engineering, University of Technology and Sciences in Bydgoszcz, Kaliskiego 7 Street, 85-789 Bydgoszcz, Poland \\ ${ }^{4}$ The Institute of Technology Fermentation and Microbiology, Faculty of Biotechnology and Food Sciences, \\ Technical University of Lodz, Wólczańska 171/173 Street, 90-924 Łódź, Poland \\ ${ }^{5}$ Department of Clinical Microbiology and Immunology, Children's Memorial Hospital, Aleja Dzieci Polskich 20, \\ 04-730 Warsaw, Poland
}

Correspondence should be addressed to Małgorzata Wiese; malgorzatawiese@gmail.com

Received 13 July 2014; Revised 11 September 2014; Accepted 15 September 2014

Academic Editor: Miguel Gueimonde

Copyright (C) 2015 Małgorzata Wiese et al. This is an open access article distributed under the Creative Commons Attribution License, which permits unrestricted use, distribution, and reproduction in any medium, provided the original work is properly cited.

\begin{abstract}
The aim of this study was to find out if selected lactic acid bacteria (LAB) strains (antagonistic or nonantagonistic against $H$. pylori in vitro) would differ in their abilities to modulate the DCs maturation profiles reflected by their phenotype and cytokine expression patterns. Methods. Monocyte-derived DCs maturation was elicited by their direct exposure to the LAB strains of L. rhamnosus 900 or L. paracasei 915 (antagonistic and nonantagonistic to H. pylori, resp.), in the presence or absence of $H$. pylori strain cagA+. The DCs maturation profile was assessed on the basis of surface markers expression and cytokines production. Results. We observed that the LAB strains and the mixtures of LAB with $H$. pylori are able to induce mature DCs. At the same time, the $L$. paracase 915 leads to high IL-10/IL-12p70 cytokine ratio, in contrast to L. rhamnosus 900 . Conclusions. This study showed that the analyzed lactobacilli strains are more potent stimulators of DC maturation than $H$. pylori. Interestingly from the two chosen LAB strains the antagonistic to $H$. pylori-L. rhamnosus strain 900 has more proinflammatory and probably antibactericidal properties.
\end{abstract}

\section{Introduction}

Treatment of H. pylori infection is a long-term and not always efficient process. Antibiotic therapy leads to eradication of this pathogen in approximately $60-90 \%$ of the cases. However, even the efficiently treated individuals are still at risk of reinfection $[1,2]$. Administration of selected strains of lactic acid bacteria (LAB), a component of intestinal microbiota, is an established factor improving efficiency of $H$. pylori eradication [3-5]. Some LAB strains prevent $H$. pylori colonization of gastric mucosa, thus decreasing the number of these bacteria in the stomach. The principle mechanism behind this effect of LAB is synthesis of lactic acid, which alters gastric $\mathrm{pH}$ and inactivates urease, a pivotal enzyme for $H$. pylori viability $[6,7]$. The antagonism between $\mathrm{LAB}$ and $H$. pylori can be also associated with synthesis of other antibacterial compounds, for example, bacteriocins, autolysins, or thermostable proteins [7]. Apart from the bacterial antagonism, recent studies center around potential immunological mechanisms through which LAB can support eradication of $H$. pylori and attenuate inflammation of gastric mucosa. These include influence of LAB on enhanced local synthesis of $\operatorname{Ig} A$, modulation of specific IgG levels $[8,9]$, and induction of pro- and anti-inflammatory cytokine profiles [10].

Acute inflammation observed during an early phase of $H$. pylori infection is characterized by enhanced production 
of proinflammatory Th1/Th17 cytokines, presence of cellmediated cytolysis, plasma cell infiltration, and synthesis of specific antibodies in the stomach and duodenum [11-14]. In turn, chronic inflammation associated with long-term gastrointestinal colonization by this pathogen is reflected by suboptimal Th1 response observed at later stages of the infection, as well as by an increase in Treg lymphocyte count [15-18]. The type of immune response is to a large extent determined by the activity of antigen-presenting cells (APCs), especially dendritic cells (DCs) which constitute a "link" between the nonspecific and specific responses [19-21]. Acute $H$. pylori infection is associated with migration of DCs to the antral mucosa [22-24]. The increased inflow of DCs during an early phase of inflammation results mainly from their ability to induce immune response against $H$. pylori. However, it is not reflected by elimination of this microorganism; phenotypic and functional changes of DCs result in development of chronic inflammation and tolerance of these cells to $H$. pylori antigens $[15,25,26]$. Therefore, two questions arose regarding whether this process could be modulated by intestinal microbiota, namely, by selected LAB strains, and whether antagonism between the latter bacteria and $H$. pylori, associated with release of antibacterial compounds, might modulate activity of the immune system. Moreover, still little is known on the immunological mechanisms associated with the development of $H$. pylori infection in presence of various strains of commensal bacteria $[5,7]$.

\section{Material and Methods}

2.1. Bacteria and Their Selection. The studied LAB strains were selected from among 29 strains of Lactobacillus casei, Lactobacillus rhamnosus, Lactobacillus paracasei, and Lactobacillus plantarum. The strains were identified by the sequencing of ribosomal RNA-encoding genes [27]. All the strains originated from the Pure Culture Collection of Industrial Microorganisms at the Technical University of Lodz (ŁOCK). The activity of interstrain antagonism was investigated using the agar slab method [28]. The method was based on the observation of parallel growth of the strains under study (the indicator $-H$. pylori cagA+ strain 95 and one of the $\mathrm{LAB}$ strains). Agar slabs of $10 \mathrm{~mm}$ in diameter were aseptically cut off from the de Man, Rogosa and Sharpe medium (MRS, Oxoid) overgrown with a lawn of LAB strain incubated for $24 \mathrm{~h}$ at $37^{\circ} \mathrm{C}, 5 \% \mathrm{CO}_{2}$, and placed on plates with WilkinsChalgren Anaerobe Agar (Oxoid) inoculated with the indicator strain $\left(10^{5}-10^{6} \mathrm{CFU} / \mathrm{mL}\right)$. After 5 days of incubation in anaerobic conditions at $37^{\circ} \mathrm{C}$, the diameters of growth inhibition zones around the agar slabs were measured. The results are given in $\mathrm{mm}$, minus the agar slab diameter (Table 1).

Finally, the study included human strains of two Grampositive bacteria, L. rhamnosus 900 and L. paracasei 915 (kindly provided by the Institute of Technology Fermentation and Microbiology, Faculty of Biotechnology and Food Sciences, Technical University of Lodz), and Gram-negative H. pylori cagA+ strain 95 (obtained from the Department of Microbiology and Clinical Immunology, The Children's Memorial Health Institute). The isolated live bacterial strains
TABLE 1: Antagonistic activity of lactic acid bacteria strains.

\begin{tabular}{|c|c|c|}
\hline Species & Strain & Growth inhibition zone $[\mathrm{mm}]$ \\
\hline \multirow{12}{*}{ Lactobacillus casei } & ŁOCK 899 & 1.7 \\
\hline & ŁOCK 901 & 0 \\
\hline & ŁOCK 902 & 0 \\
\hline & ŁOCK 903 & 0 \\
\hline & ŁOCK 904 & 0 \\
\hline & ŁOCK 905 & 1.7 \\
\hline & ŁOCK 906 & 2.1 \\
\hline & ŁOCK 907 & 0 \\
\hline & ŁOCK 908 & 4.8 \\
\hline & ŁOCK 909 & 0 \\
\hline & ŁOCK 910 & 0 \\
\hline & ŁOCK 911 & 2.5 \\
\hline $\begin{array}{l}\text { Lactobacillus } \\
\text { rhamnosus }\end{array}$ & ŁOCK $900^{*}$ & 5.21 \\
\hline \multirow{13}{*}{$\begin{array}{l}\text { Lactobacillus } \\
\text { paracasei }\end{array}$} & ŁOCK 912 & 0 \\
\hline & ŁOCK 913 & 2.9 \\
\hline & ŁOCK 914 & 0 \\
\hline & ŁOCK $915^{*}$ & 0 \\
\hline & ŁOCK 916 & 2.9 \\
\hline & ŁOCK 917 & 1.6 \\
\hline & ŁOCK 918 & 2.7 \\
\hline & ŁOCK 919 & 3.6 \\
\hline & ŁOCK 920 & 2.2 \\
\hline & ŁOCK 921 & 1.7 \\
\hline & LOCK 922 & 0 \\
\hline & ŁOCK 923 & 0 \\
\hline & ŁOCK 924 & 0 \\
\hline \multirow{3}{*}{$\begin{array}{l}\text { Lactobacillus } \\
\text { plantarum }\end{array}$} & ŁOCK 862 & 2.3 \\
\hline & ŁOCK 864 & 0 \\
\hline & ŁOCK 943 & 1.6 \\
\hline
\end{tabular}

${ }^{*}$ The selected strains.

or their combinations were used as stimulating agents in all the experiments.

2.2. Generation of Human Monocyte-Derived Dendritic Cells. Peripheral blood mononuclear cells (PBMCs) were isolated from buffy coat of healthy volunteers (from the Blood Centre in Bydgoszcz, Poland) by means of Lymphocyte Separation Medium 1077 (LSM, PAA) gradient centrifugation. Monocyte-derived DCs were generated from monocytes $\left(\mathrm{CD} 14^{+}\right.$cells) isolated with an aid of CD14 beads (Becton Dickinson, positive selection), as previously described [29$32]$. The purity of the cells was greater than $95 \%$. Subsequently, the isolated cells $\left(1 \times 10^{6} / \mathrm{mL}\right)$ were cultured in RPMI 1640 (PAA) with $2 \%$ human serum $(\mathrm{AB}, \mathrm{Rh}+$ serum from the Blood Centre in Bydgoszcz, Poland) at $37^{\circ} \mathrm{C}$ and $5 \% \mathrm{CO}_{2}$ for 6 days. IL-4 (50 ng/mL, R\&D) and granulocyte-macrophage colony-stimulating factor (GM-CSF, $100 \mathrm{ng} / \mathrm{mL}, \mathrm{R} \& \mathrm{D}$ ) were 
TABLE 2: Expression of chosen receptors (CD14, HLA-DR, CD80, CD83, CD86, CD40, and CD11c) on monocyte-derived DCs surface.

\begin{tabular}{|c|c|c|c|c|c|c|c|}
\hline Receptor type & CD14 & HLA-DR & CD80 & CD83 & CD86 & $\mathrm{CD} 40$ & CD11c \\
\hline \multicolumn{8}{|l|}{ iDC } \\
\hline$\%$ & $\begin{array}{c}1.98 \\
{[0.38-1.99]}\end{array}$ & $\begin{array}{c}97.11 \\
{[89.30-99.55]}\end{array}$ & $\begin{array}{c}4.99 \\
{[2.88-5.73]}\end{array}$ & $\begin{array}{c}1.27 \\
{[0.89-3.32]}\end{array}$ & $\begin{array}{c}98.55 \\
{[97.25-99.70]}\end{array}$ & $\begin{array}{c}26.4 \\
{[12.10-37.95]}\end{array}$ & $\begin{array}{c}98.7 \\
{[97.50-99.00]}\end{array}$ \\
\hline GFI & $\begin{array}{c}183 \\
{[146-220]}\end{array}$ & $\begin{array}{c}336 \\
{[274-363]}\end{array}$ & $\begin{array}{c}181 \\
{[170-188]}\end{array}$ & $\begin{array}{c}150 \\
{[145-160]}\end{array}$ & $\begin{array}{c}463 \\
{[350-581]}\end{array}$ & $\begin{array}{c}160 \\
{[130-190]}\end{array}$ & $\begin{array}{c}676 \\
{[650-793]}\end{array}$ \\
\hline
\end{tabular}

DCs: dendritic cells; iDCs: immature DCs; \%: the percentage of DCs expressing the analyzed receptor; GFI: geometric mean fluorescence intensity of the analyzed receptor in DCs population exhibiting its expression; values are expressed as the medians of six independent experiments and range of lower quartileupper quartile [Q1-Q3].

added to the culture medium in order to stimulate DCs development.

2.3. Dendritic Cells Stimulation. The DCs $\left(1 \times 10^{6} / \mathrm{mL}\right)$ were suspended in $1 \mathrm{~mL}$ of RPMI 1640 (PAA) supplemented with $2 \%$ human serum $(\mathrm{AB}, \mathrm{Rh}+$ serum provided by the Blood Centre in Bydgoszcz, Poland) and incubated at $37^{\circ} \mathrm{C}$ and $5 \% \mathrm{CO}_{2}$ in presence of $H$. pylori, L. rhamnosus 900, $L$. paracasei 915 , L. rhamnosus $900+H$. pylori, or L. paracasei $915+H$. pylori. The DCs were incubated with bacteria or medium alone (control DCs) for $24 \mathrm{~h}$. The DC to bacterial cell ratio was $1: 10$. The live bacteria at concentrations providing optimal maturity and viability of DCs (not shown) were used as stimulating agents in all the experiments. The cells were collected by gentle pipetting and centrifuged at $250 \times \mathrm{g}$ for $10 \mathrm{~min}$. The culture supernatant was collected and stored at $-80^{\circ} \mathrm{C}$ until cytokine analysis. The cells were resuspended in PBS, and trypan blue exclusion test showed that the culture contained $90 \%$ of viable cells.

2.4. Cell Surface Phenotype Expression. Subsequently, the cells were stained for CD14, CD11c, CD80, CD86, and CD40 (all from Becton Dickinson) using mouse antihuman monoclonal antibodies conjugated with fluorescein isothiocyanate (FITC), phycoerythrin (PE), or peridininchlorophyll proteins (PercP). A total of 20000 events were collected according to the manufacturer's procedure that was described elsewhere [33]. The cells were subjected to flow cytometric analysis with FACScan flow cytometer (Becton Dickinson), and the cytometric data were analyzed using FlowJo version 7.6.1 software (Tree Star). The percentage of cells showing expression of the studied receptors and the average receptor density expressed as the geometric mean of fluorescence intensity (GFI) were analyzed in a population of DCs.

2.5. Cytokine Assay. Cytokine concentrations in DCs cell culture supernatants were estimated following $24 \mathrm{~h}$ of bacterial or medium alone (control DCs) stimulation. The cytokine levels were measured by means of commercially available ELISA kits: DuoSet, BD Bioscience (IL-12p70, IL10 , and TNF- $\alpha$ ), and R\&D Systems (IL-23), according to the manufacturer's instructions. Before performing the tests, the supernatant samples were diluted according to each kit's protocol and the final results were obtained by appropriate multiplication. The protein level in the diluted sample was calculated from a reference curve generated for a given assay by using reference standards containing known concentrations of appropriate protein. Results were expressed as pg per $\mathrm{mL}$. The range of cytokine detection was as follows: from 7.8 to $500 \mathrm{pg} / \mathrm{mL}$ for IL-12p70, IL-10, TNF-alfa and from $125 \mathrm{pg} / \mathrm{mL}$ to $8000 \mathrm{pg} / \mathrm{mL}$ for IL-23.

2.6. Statistics. Statistical analysis was conducted with Statistica 9.0 software (StatSoft). The normal distribution was checked using the Shapiro-Wilk test. Due to the nonnormal distribution of the data, Mann-Whitney $U$ test was performed. Statistical significance was considered at $P<0.05$.

\section{Results}

3.1. The Antagonistic Spectrum of LAB Strains. Antagonistic effect of LAB strains was tested against $H$. pylori cagA+ strain 95 . The antagonistic activity of Lactobacillus spp. was examined with the agar slab method, which is based on analysis of simultaneous growth of the indicator strain $(H$. pylori cagA+ strain 95) and a tested strain (LAB). The results of the slab culture constituted the basis for selection of the studied strains of LAB. The strongest antagonistic effect against $H$. pylori, manifested by a $5.21 \mathrm{~mm}$ zone of inhibition, was documented in the case of L. rhamnosus 900. Finally, two strains of $\mathrm{LAB}$ were selected for further analyses: $L$. rhamnosus 900 , antagonistic to $H$. pylori, and the nonantagonistic L. paracasei 915 .

3.2. Phenotype of Monocyte-Derived DCs. Monocyte-derived DCs were analyzed for surface phenotype by flow cytometry. Cells grown in GM-CSF and IL-4 alone after 6 days were immature, as defined by lack expression of CD14, relatively to stimulated DCs poor expression of CD83 and CD80 (Table 3) and lower expression of CD40, HLA-DR, and CD86. Almost all monocyte-derived DCs had expression of CD11c, characteristic marker for myeloid DCs (Figure 1, Table 2).

3.3. Phenotype of Bacteria-Stimulated DCs. Differences in the expression of DCs surface molecules were analyzed after one day of the bacterial stimulation (LAB strains: L. rhamnosus 900, L. paracasei 915; H. pylori; mixture: L. rhamnosus $900+$ H. pylori and L. paracasei $915+H$. pylori) (Table 3).

Compared to the unstimulated DCs (control DCs), bacteria-stimulated DCs (irrespective of their variant) were 


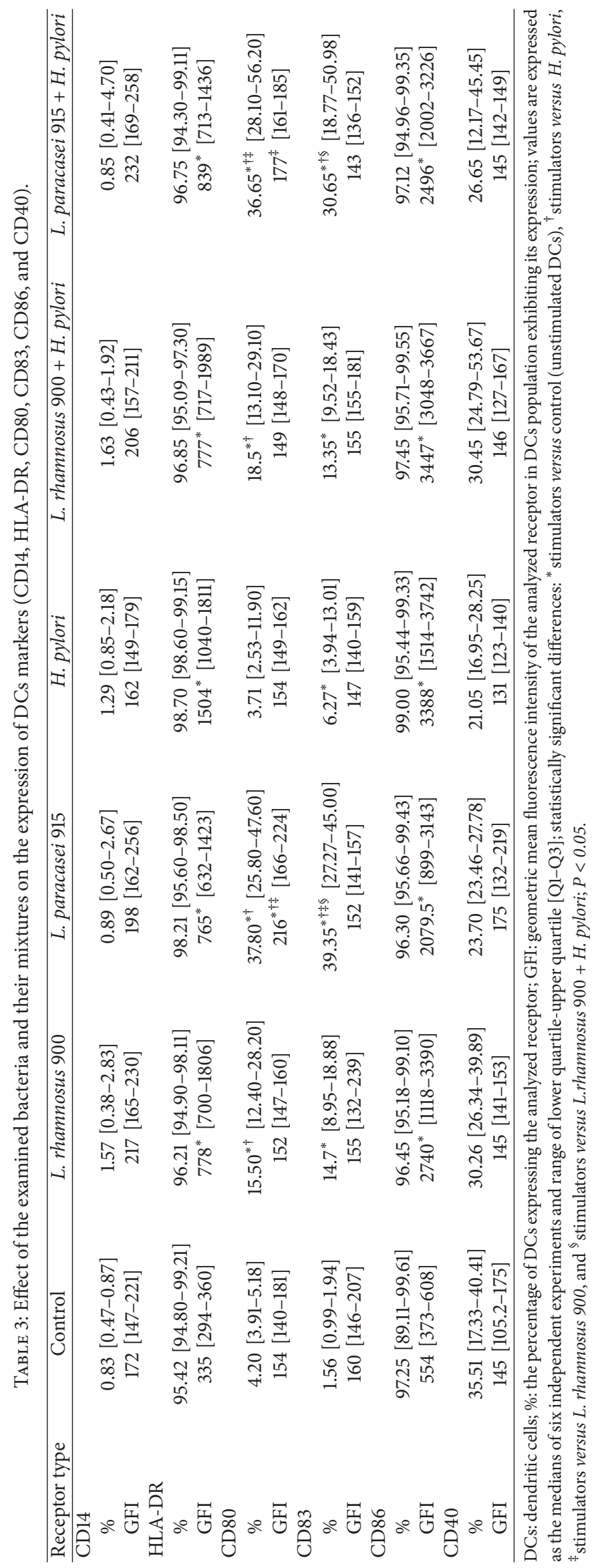




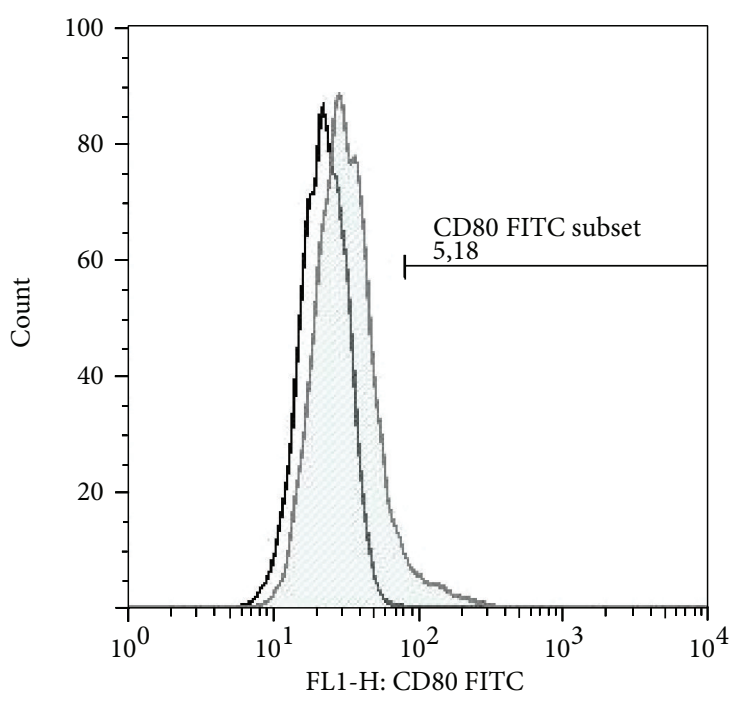

(a)

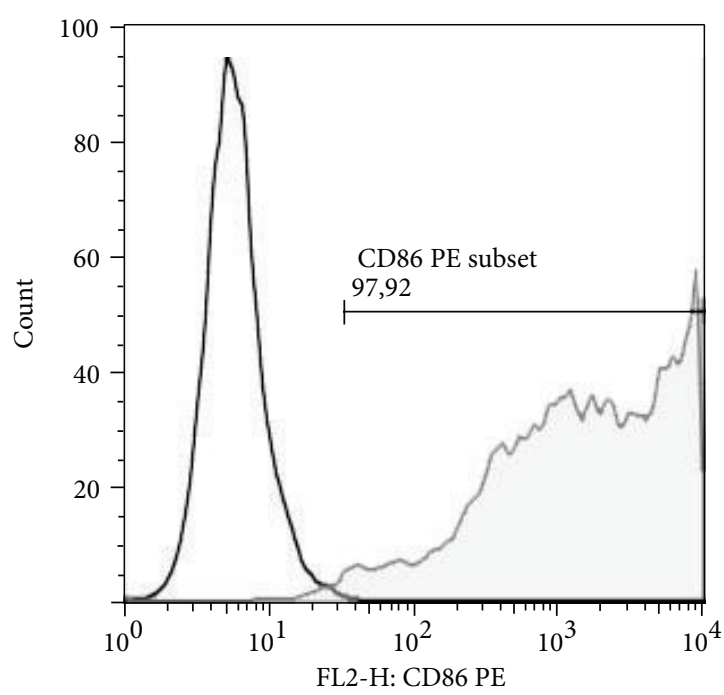

(c)

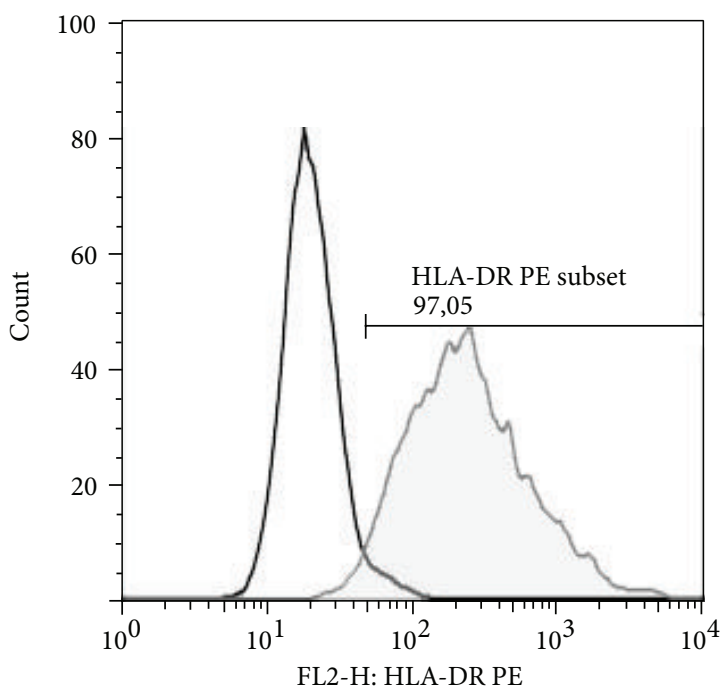

(e)

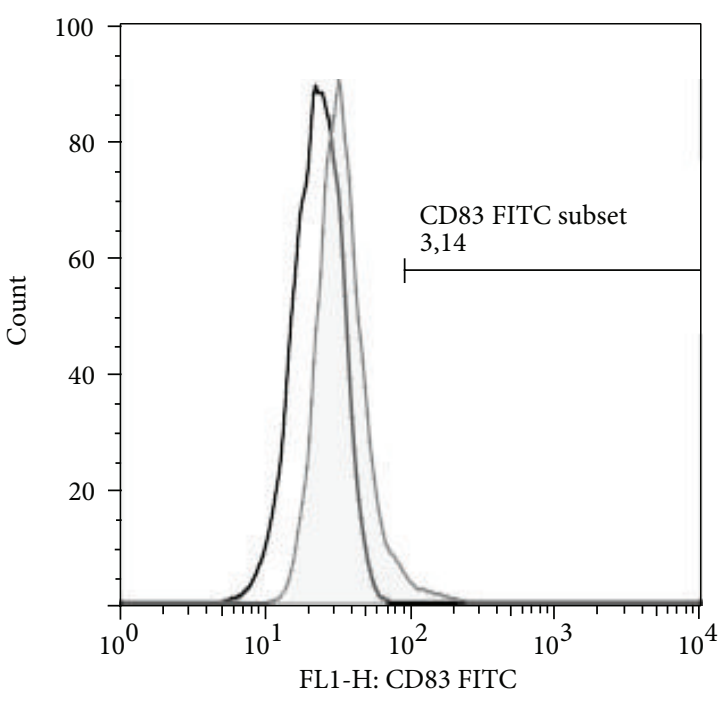

(b)

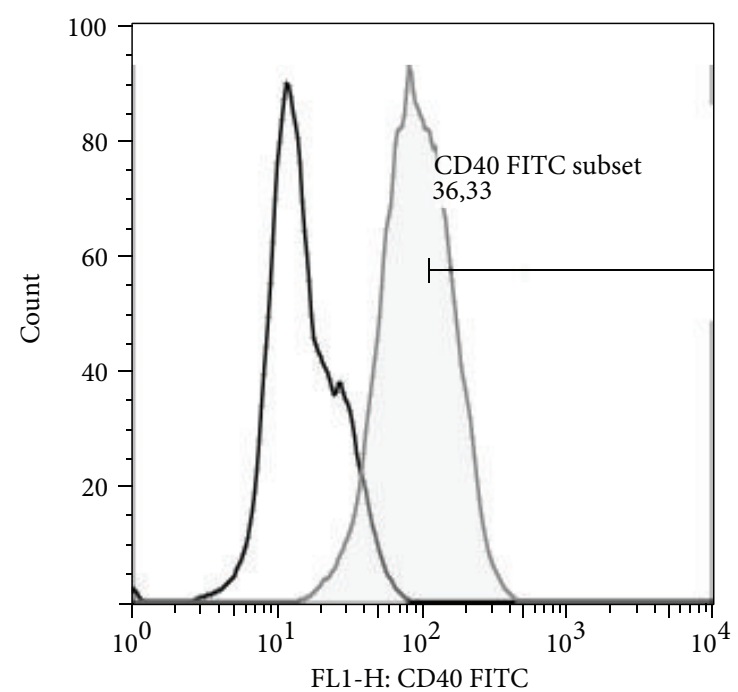

(d)

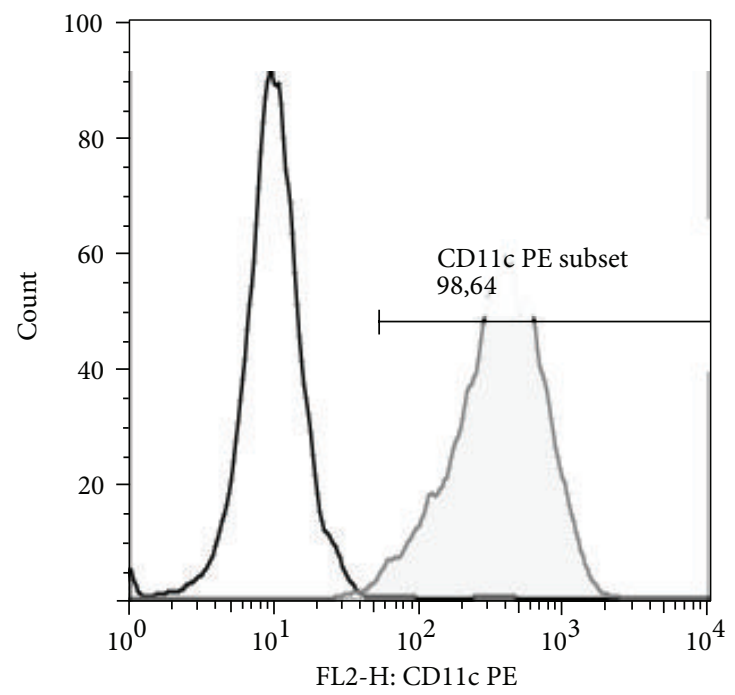

(f)

FIGURE 1: Phenotype of immature DCs. Histograms of representative cytometric data illustrate the following: (a) percentage of CD80 $0^{+}$DCs; (b) percentage of $\mathrm{CD} 83^{+} \mathrm{DCs}$, (c) percentage of $\mathrm{CD} 86^{+} \mathrm{DCs}$; (d) percentage of CD40 ${ }^{+} \mathrm{DCs}$; (e) percentage of HLA-DR ${ }^{+} \mathrm{DCs}$; and (f) percentage of CD11c ${ }^{+}$DCs. DCs: dendritic cells; stimulated DCs are represented by filled curves; isotype controls are represented by empty curves. 

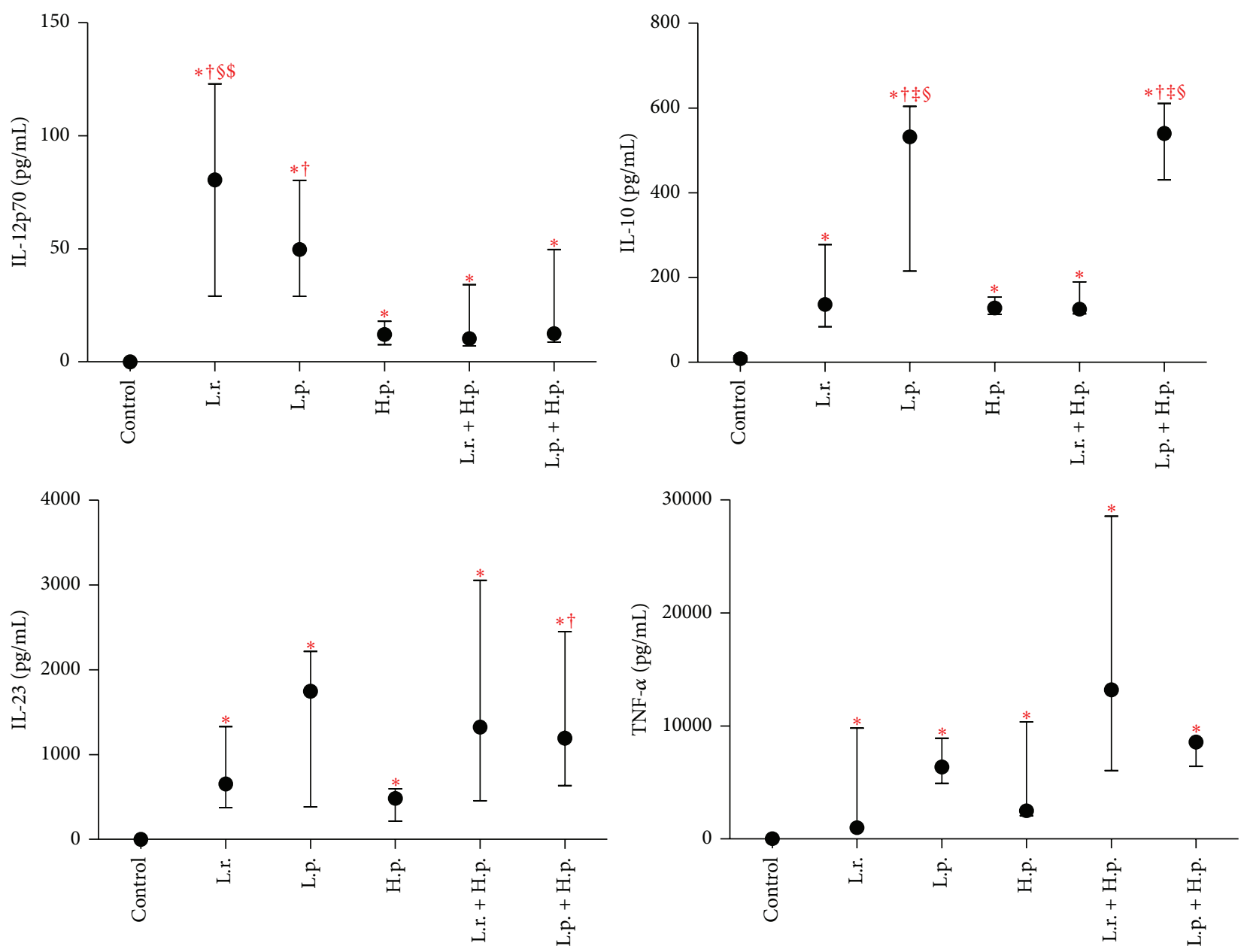

FIGURE 2: Effect of the examined bacteria and their mixtures on the production of cytokines by DCs population. Values expressed as medians from six independent experiments and interquartile ranges [Q1-Q3]; control: unstipulated DCs; L.r.: L. rhamnosus 900; L.p.: L. paracasei 915; H.p.: H. pylori; statistically significant differences are given as follows: $*$ : stimulators versus control (unstimulated DCs), $\dagger$ : stimulators versus H. pylori, $\ddagger$ : stimulators versus L. rhamnosus 900 , \$: stimulators versus L. rhamnosus $900+H$. pylori, and \$: stimulators versus L. paracasei 915 + H. pylori; $P<0.05$; DCs: dendritic cells.

reflected by a significant increase in HLA-DR and CD86 receptor densities on DCs (GFI for CD86 and GFI for HLADR).

Furthermore, the stimulation with either single bacterial strain caused a significant increase in the percentage of CD83positive cells but the highest percentage of these cells was observed after stimulation with $L$. paracasei 915 . A mixture of $L$. paracasei $915+H$. pylori turned out to exert stronger stimulatory effect on the expression of CD83-positive DCs than $H$. pylori alone or the mixture of L. rhamnosus 900 and H. pylori.

A significant increase in the percentage of CD80-positive DCs was observed solely after exposure of DCs to LAB strains alone or in combination with $H$. pylori. In turn, $H$. pylori alone turned out to be significantly weaker inducer of the CD80-positive cells than the LAB strains and their mixtures. Moreover, we showed that exposure to L. paracasei 915 was reflected by significantly higher increase in density of CD80 receptor (GFI for CD80 receptor) than in the case of stimulation with $H$. pylori. Both L. paracasei 915 alone and in the mixture with $H$. pylori caused significantly greater increase in GFI for CD80 than did L. rhamnosus 900.

3.4. Comparison of Cytokine Levels after Bacterial Stimulation. The DCs were stimulated for $24 \mathrm{~h}$ with live bacteria, either a single strain or a mixture of two bacterial strains (Figure 2). All the stimulators effectively induced cytokine synthesis (IL10, IL-12p70, IL-23, and TNF- $\alpha$ ) when compared with control DCs (unstimulated DCs).

L. rhamnosus 900 alone turned out to be stronger inducer of IL-12p70 than $H$. pylori alone and mixtures of $H$. pylori + LAB. Also another analyzed LAB strain, L. paracasei 915, proved to be better stimulator of IL-12p70 synthesis than $H$. pylori.

Furthermore, the stimulation with either $L$. paracasei 915 alone or its combination with $H$. pylori was reflected by significantly more enhanced synthesis of IL-10 than the exposure to L. rhamnosus 900 , L. rhamnosus $900+H$. pylori, and $H$. pylori alone. 


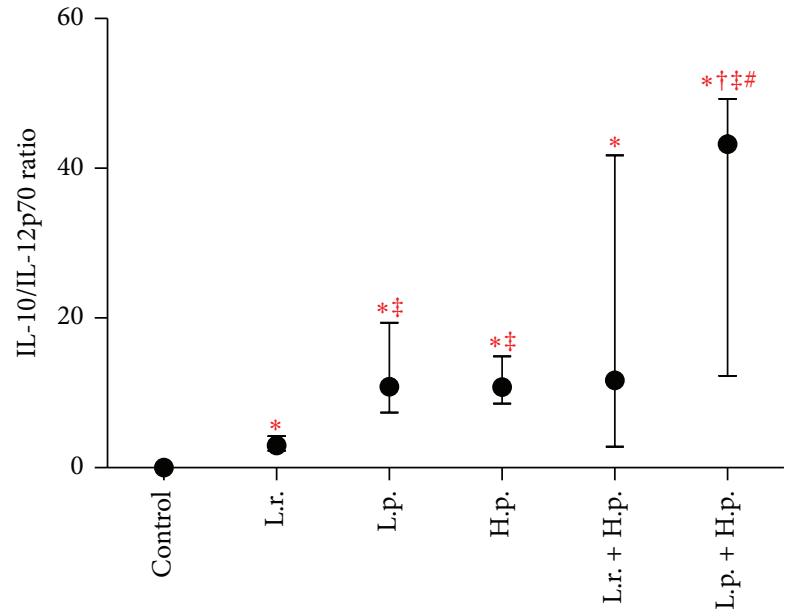

FIGURE 3: The cytokine IL-10/IL-12p70 ratio. Values expressed as medians from the ratios from six independent experiments and interquartile ranges [Q1-Q3]; control: unstipulated DCs; L.r.: L. rhamnosus 900; L.p.: L. paracasei 915 ; and H.p.: H. pylori; statistically significant differences are given as follows: $*$ : stimulators versus control (unstimulated DCs), $\dagger$ : stimulators versus $H$. pylori, $\ddagger$ : stimulators versus L. rhamnosus 900, stimulators versus L. paracasei 915; $P<0.05$; DCs: dendritic cells.

Finally, stimulation of DCs with any of bacterial strains or their mixtures caused an increase in the synthesis of IL-23. However, $H$. pylori alone turned out to be a weaker stimulator of IL-23 versus L. paracasei $915+H$. pylori $(P<0.05)$ and $L$. rhamnosus $900+H$. pylori $(P<0.1)$.

Stimulation with all the bacteria and their mixtures resulted in a significant increase in TNF- $\alpha$ concentration, but without statistical differences.

Next, we calculated the IL-10/IL-12p70 ratios obtained from these studies (Figure 3). These allowed the ranking of the strains from an "anti-inflammatory" to a "proinflammatory" profile. The strains L. paracasei 915 and H. pylori were classified as more anti-inflammatory. L. rhamnosus 900 showed a slightly proinflammatory profile with a very low IL10/IL-12p70 ratio. The mixture L. paracasei $915+H$. pylori showed strong anti-inflammatory capability. In contrast, despite the rather high ratio of IL-10/IL-12p70, the mixture $L$. rhamnosus $900+H$. pylori did not show differences between stimulators.

\section{Discussion}

In this study, we provided evidence for the immunostimulatory effect of LAB strains on $H$. pylori-induced DCs. We also reported for the first time that the LAB strains induce more mature phenotype of DCs than $H$. pylori alone (as shown by greater percentage of $\mathrm{CD} 80^{+} \mathrm{DCs}$ ). Thus, our findings point to potential application of some of these bacteria as a component of $H$. pylori infection treatment.

There are three consecutive stages of DC maturation: immature DCs (iDCs), semimature DCs (smDCs), and mature DCs (mDCs). The cells representing these phenotypes can be distinguished on the basis of cytometric analysis of
HLA-DR, CD80, CD86, CD83, and CD40 receptor expressions and profile of secreted cytokines, such as IL-10, IL12 p70, IL-23, and TNF- $\alpha$ [34-36]. Activation of iDCs with foreign antigens, for example, bacterial Ag, results in their transformation to smDCs or mDCs. The phenotype of semimature DCs does not differ from that of mDCs: their ability to synthesize cytokines is limited as shown by markedly lower concentrations of proinflammatory cytokines and moderate level of IL-10 in culture supernatant. In contrast, the fully mature DCs cause activation of T cell response and synthesize an array of cytokines, for example, IL-12p70, IL-12p40, IL6 , and TNF- $\alpha[34,35,37]$. It is noteworthy that all DCs constitutively express CD86 and HLA-DR on their surfaces $[38,39]$. Therefore, we identified iDCs, mDCs, and smDCs on the basis of percentage of cells expressing CD83 and CD80 and fluorescence intensity of these receptors on DC surface as well as cytokine production.

The increase in the percentage of $\mathrm{CD} 83^{+}$cells, observed after stimulation with either all the analyzed bacteria $(H$. pylori, LAB) or their mixtures (LAB with $H$. pylori), likely reflected the process of DC maturation $[31,40]$. L. paracasei 915, that is, the strain nonantagonistic to $H$. pylori, turned out to be the most potent activator of DC maturation among all the analyzed variants, as shown by the most pronounced increase in the percentage of $\mathrm{CD} 83^{+}$cells and density of CD80. Analysis of the expression of CD80 receptor, responsible for late activation of DCs [38], showed that $H$. pylori was the only bacterium that did not stimulate an increase in the percentage of $\mathrm{CD} 80^{+}$cells. Therefore, the analyzed strain of $\mathrm{H}$. pylori stimulated maturation of DCs to a lesser extent, which likely corresponded to development of smDCs with tolerogenic phenotype $[41,42]$. In contrast, the mixtures of $H$. pylori with the LAB strains stimulated differentiation of CD80-positive DCs. Therefore, the analyzed lactobacilli likely enhanced the process of DCs maturation despite the presence of $H$. pylori. This phenomenon may directly affect the following: (a) presentation of $\mathrm{Ag}$ to antigen-naive lymphocytes $\mathrm{T}$, (b) profile of secreted cytokines, and (c) characteristics of Tdependent response (e.g., predominance of Th1, Th2, or Th17 response).

It is commonly known that the effective response of $\mathrm{T}$ lymphocytes requires two types of activation signal: (a) interaction between Ag presented by MHC I/II and the TCR/CD3 receptor and (b) interaction between receptors, such as CD80, CD86, and CD28 or CTLA-4. Too weak second signal leads to anergy of $\mathrm{T}$ lymphocytes and resultant apoptosis thereof $[38,43]$. The abovementioned process involves a number of molecules supporting the presentation, such as CD40 and CD83 participating in activation of T lymphocytes [44, 45]. Although we documented an increase in the percentage of $\mathrm{CD}^{2} 3^{+}$cells in DC population, both relative and absolute numbers of $\mathrm{CD} 40^{+}$cells remained unchanged. Moreover, it should be stressed that all the analyzed strains and the mixtures thereof exerted similar effect on CD86 and HLADR expressions. These findings suggest that we did not obtain fully mature DCs since, as mentioned previously, the presence of the latter needs to be confirmed by secretion of specific cytokines to culture supernatant. Apart from maturation of DCs, also polarization of these cells toward DC1 or 
DC2 function constitutes equally important component of response to $H$. pylori infection; the process of polarization can be analyzed on the basis of concentrations of selected cytokines, especially IL-12p70 and IL-10. The fact that the level of biologically active form of IL-12 after stimulation with $H$. pylori alone was lower than after the exposure to the analyzed LAB strains may reflect immunosuppressive effect of $H$. pylori or polarization of DC towards Th2 response [15]. It should be emphasized that the mixtures of analyzed $\mathrm{LAB}$ strains (L. rhamnosus 900 and L. paracasei 915 ) and H. pylori induced secretion of IL-12p70 at a similar level as did $H$. pylori alone, which suggests that the latter bacterium might inhibit the LAB-induced immune response. This hypothesis is supported by the results of a previous study in which $H$. pylori was shown to release a factor that inhibited secretion of IL-12 by DCs $[24,46]$. However, despite the fact that IL23 belongs to the family of IL-12, similar effects were not observed. We showed that the level of IL-23 after stimulation with $L$. paracasei 915 and $H$. pylori mixture was significantly higher than in the case of exposure to $H$. pylori alone. In turn, the concentration of IL- 23 in the culture of DCs stimulated with the mixture of $L$. rhamnosus 900 and $H$. pylori turned out to be similar as in the case of DCs induced with $L$. paracasei 915 and H. pylori. High level of IL-23 corresponds to proinflammatory function of activated DCs and can be associated with induction of Th17 response [47, 48]. The DCs stimulated with the bacterial mixtures seemed to be more effective and their phenotype resembled that of mDCs to a larger extent than the phenotype of the cells exposed to H. pylori alone. Enhanced synthesis of IL-23, involved in the control of Th17 response, may be beneficial in the case of $H$. pylori-induced inflammation as previous studies showed that it improves the antibacterial potential $[13,22]$. Apart from IL-23, DCs synthesize an array of other proinflammatory cytokines, for example, TNF- $\alpha$ [49]. Both $\mathrm{LAB}$ and $H$. pylori, as well as their mixtures, enhanced synthesis of TNF- $\alpha$; however, the levels of this cytokine did not differ significantly between the analyzed culture variants. Previous studies showed that bacterial stimulation of DCs is reflected by enhanced synthesis of TNF- $\alpha$; this cytokine exerts pleiotropic effects [50-55], determined by duration of the exposure. Moreover, high level of TNF- $\alpha$ was shown to be a marker of DC maturation. It is interesting that mature DCs can also synthesize these cytokines that act antagonistically to proinflammatory cytokines, for example, IL-10 [56]. Both L. paracasei 915 strain and the mixture thereof with $H$. pylori turned out to be the strongest inductors of IL-10 synthesis. These findings confirm that a nonantagonistic strain can stimulate tolerogenic response associated with activation of type- 2 polarized DCs. The concentration of IL10 documented after stimulation with $H$. pylori was markedly lower, similar to that observed after exposure to L. rhamnosus 900 alone or in mixture with $H$. pylori. As mentioned above, low level of this cytokine may be characteristic for smDCs [34], which further confirms that stimulation with $H$. pylori promotes tolerogenic phenotype of DCs. Low levels of both IL-10 and IL-12p70 in H. pylori-induced culture may also point to the lack of DC polarization and result in the lack of their reactivity with T lymphocytes. However, the hereby presented findings suggest that such dysregulation of immune response may be at least partially counterbalanced by LAB strains, as shown by increased expression of DC surface markers (CD80 and/or CD83) and higher concentration of IL-23 in culture supernatant.

The fact that LAB stimulated maturation of DCs suggests that these bacteria may normalize immune mucosal function during symptomatic $H$. pylori infection. However, we could not unambiguously distinguish which of the LAB strains, antagonistic or nonantagonistic one, was a stronger enhancer of antibacterial reaction associated with activation of T-dependent (Thl, Th17) response. On one hand, we documented a marked increase in CD80 expression solely on the surface of DCs stimulated with L. paracasei 915 and its mixture with $H$. pylori, which points to greater potential of the nonantagonistic LAB strainas a stimulator of DC maturation. On the other hand, the same LAB strain proved to be a strong inductor of IL-10 synthesis. In turn, this cytokine is known to stimulate response of Treg lymphocytes [57], and percentage of these latter cells increases in the course of $H$. pylori infection, being tightly associated with the activity and phenotype of DCs. In contrast, elimination of Tregs may promote eradication of $H$. pylori [58]. Therefore, lower mucosal counts of Tregs will be reflected by stronger immune response (Th1 or Th17 response) and resultant elimination of H. pylori. Understanding the profile of T lymphocyte in the coculture of these cells with $\mathrm{LAB} / H$. pylori-stimulated DCs is warranted (actually under study). However, L. rhamnosus 900 in contrast to $L$. paracasei 915 shows reduced IL-10/IL-12p70 ratio. Therefore, it seems that nonantagonistic strain may be more supressive/tolerogenic. It should be noted also that the mixture L. paracasei $915+H$. pylori was also strongly antiinflammatory. Taking together, L. rhamnosus 900 proved to be a weaker stimulator of DC maturation, the polarization of cellular response induced by this bacterium could be more beneficial in the context of $H$. pylori infection.

\section{Conclusions}

First, the LAB strains used here were much more potent DC maturation agents than H. pylori. Second, H. pyloriinduced DCs tolerogenic phenotype was at least partially overcome by the LAB strains. Third, the L. rhamnosus strain 900 (antagonistic to $H$. pylori) proved to be more effective than L. paracasei strain 915 (nonantagonistic to H. pylori) in DCs protection against tolerogenic action of $H$. pylori.

\section{Conflict of Interests}

The authors declare that there is no conflict of interests regarding the publication of this paper.

\section{Acknowledgments}

This work was supported by Scholarships for Ph.D. Student 2008/2009-IROP, "Step into the Future," Scholarships for Ph.D. Students III Edition 2010/2011, the Ph.D. Scholarship Development EFS, Grant for young scientists CM UMK no. 
MN-3/WF-SD, and Grant for statutory activities no. 837 from CM UMK.

\section{References}

[1] T. G. Blanchard, J. C. Eisenberg, and Y. Matsumoto, "Clearance of Helicobacter pylori infection through immunization: the site of T cell activation contributes to vaccine efficacy," Vaccine, vol. 22, no. 7, pp. 888-897, 2004.

[2] K. Dzierzanowska-Fangrat, E. Rozynek, D. Celinska-Cedro et al., "Antimicrobial resistance of Helicobacter pylori in Poland: a multicentre study," International Journal of Antimicrobial Agents, vol. 26, no. 3, pp. 230-234, 2005.

[3] B.-S. Sheu, H.-C. Cheng, A.-W. Kao et al., "Pretreatment with Lactobacillus- and Bifidobacterium-containing yogurt can improve the efficacy of quadruple therapy in eradicating residual Helicobacter pylori infection after failed triple therapy," The American Journal of Clinical Nutrition, vol. 83, no. 4, pp. 864-869, 2006.

[4] C. P. Felley, I. Corthésy-Theulaz, J.-L. Blanco Rivero et al., "Favourable effect of an acidified milk (LC-1) on Helicobacter pylori gastritis in man," European Journal of Gastroenterology and Hepatology, vol. 13, no. 1, pp. 25-29, 2001.

[5] M. Gotteland, O. Brunser, and S. Cruchet, "Systematic review: are probiotics useful in controlling gastric colonization by Helicobacter pylori?" Alimentary Pharmacology and Therapeutics, vol. 23, no. 8, pp. 1077-1086, 2006.

[6] K. Stingl, E.-M. Uhlemann, G. Deckers-Hebestreit, R. Schmid, E. P. Bakker, and K. Altendorf, "Prolonged survival and cytoplasmic $\mathrm{pH}$ homeostasis of Helicobacter pylori at $\mathrm{pH} 1$," Infection and Immunity, vol. 69, no. 2, pp. 1178-1181, 2001.

[7] D. Lesbros-Pantoflickova, I. Corthésy-Theulaz, and A. L. Blum, "Helicobacter pylori and probiotics," Journal of Nutrition, vol. 137, supplement 2, no. 3, pp. 812S-818S, 2007.

[8] E. Vitiñi, S. Alvarez, M. Medina, M. Medici, M. V. de Budeguer, and G. Perdigón, "Gut mucosal immunostimulation by lactic acid bacteria," Biocell, vol. 24, no. 3, pp. 223-232, 2000.

[9] D. Sgouras, P. Maragkoudakis, K. Petraki et al., "In vitro and in vivo inhibition of Helicobacter pylori by Lactobacillus casei strain Shirota," Applied and Environmental Microbiology, vol. 70, no. 1, pp. 518-526, 2004.

[10] T. von der Weid, C. Bulliard, and E. J. Schiffrin, "Induction by a lactic acid bacterium of a population of CD4+ T cells with low proliferative capacity that produce transforming growth factor $\beta$ and interleukin-10," Clinical and Diagnostic Laboratory Immunology, vol. 8, no. 4, pp. 695-701, 2001.

[11] A. Helmin-Basa, J. Michalkiewicz, L. Gackowska et al., "Pediatric Helicobacter pylori infection and circulating Tlymphocyte activation and differentiation," Helicobacter, vol. 16, no. 1, pp. 27-35, 2011.

[12] A. Helmin-Basa, M. Czerwionka-Szaflarska, G. Bala et al., "Expression of adhesion and activation molecules on circulating monocytes in children with Helicobacter pylori infection," Helicobacter, vol. 17, no. 3, pp. 181-186, 2012.

[13] S. Kabir, "The role of interleukin-17 in the Helicobacter pylori induced infection and immunity," Helicobacter, vol. 16, no. 1, pp. $1-8,2011$.

[14] D. Bimczok, R. H. Clements, K. B. Waites et al., "Human primary gastric dendritic cells induce a Th1 response to $H$. pylori," Mucosal Immunology, vol. 3, no. 3, pp. 260-269, 2010.
[15] P. Mitchell, C. Germain, P. L. Fiori et al., "Chronic exposure to Helicobacter pylori impairs dendritic cell function and inhibits Th1 development," Infection and Immunity, vol. 75, no. 2, pp. 810-819, 2007.

[16] R. Karttunen, T. Karttunen, H.-P. T. Ekre, and T. T. MacDonald, "Interferon gamma and interleukin 4 secreting cells in the gastric antrum in Helicobacter pylori positive and negative gastritis," Gut, vol. 36, no. 3, pp. 341-345, 1995.

[17] M. Mohammadi, S. Czinn, R. Redline, and J. Nedrud, "Helicobacter-specific cell-mediated immune responses display a predominant Th1 phenotype and promote a delayed-type hypersensitivity response in the stomachs of mice," Journal of Immunology, vol. 156, no. 12, pp. 4729-4738, 1996.

[18] A. Lundgren, E. Suri-Payer, K. Enarsson, A.-M. Svennerholm, and B. S. Lundin, "Helicobacter pylori-specific $\mathrm{CD} 4{ }^{+} \mathrm{CD} 25^{\text {high }}$ regulatory $\mathrm{T}$ cells suppress memory $\mathrm{T}$-cell responses to $\mathrm{H}$. pylori in infected individuals," Infection and Immunity, vol. 71, no. 4, pp. 1755-1762, 2003.

[19] O. Pabst and A. M. Mowat, "Oral tolerance to food protein," Mucosal Immunology, vol. 5, no. 3, pp. 232-239, 2012.

[20] T. W. Spahn and T. Kucharzik, "Modulating the intestinal immune system: the role of lymphotoxin and GALT organs," Gut, vol. 53, no. 3, pp. 456-465, 2004.

[21] C. W. Cutler and R. Jotwani, "Dendritic cells at the oral mucosal interface," Journal of Dental Research, vol. 85, no. 8, pp. 678-689, 2006.

[22] J. Y. Kao, M. Zhang, M. J. Miller et al., "Helicobacter pylori immune escape is mediated by dendritic cell-induced Treg skewing and Th17 suppression in mice," Gastroenterology, vol. 138, no. 3, pp. 1046-1054, 2010.

[23] M. L. Drakes, S. J. Czinn, and T. G. Blanchard, "Regulation of murine dendritic cell immune responses by Helicobacter felis antigen," Infection and Immunity, vol. 74, no. 8, pp. 4624-4633, 2006.

[24] J. Y. Kao, S. Rathinavelu, K. A. Eaton et al., "Helicobacter pylori-secreted factors inhibit dendritic cell IL-12 secretion: a mechanism of ineffective host defense," The American Journal of Physiology-Gastrointestinal and Liver Physiology, vol. 291, no. 1, pp. G73-G81, 2006.

[25] M. Zhang, B. E. Berndt, K. A. Eaton, S. Rathinavelu, A. Pierzchala, and J. Y. Kao, "Helicobacter pylori-pulsed dendritic cells induce H. pylori-specific immunity in mice," Helicobacter, vol. 13, no. 3, pp. 200-208, 2008.

[26] M. Zhang, M. Liu, J. Luther, and J. Y. Kao, "Helicobacter pylori directs tolerogenic programming of dendritic cells," Gut Microbes, vol. 1, no. 5, pp. 325-329, 2010.

[27] T. Aleksandrzak-Piekarczyk, A. Koryszewska-Baginska, and J. Bardowski, "Genome sequence of the probiotic strain Lactobacillus rhamnosus (formerly Lactobacillus casei) LOCK900," Genome Announcements, vol. 1, no. 4, 2013.

[28] M. Strus, "A new method for evaluation of the antagonistic action of bacterial lactic acid (LAB) on selected pathogenic indicator bacteria," Medycyna Doświadczalna i Mikrobiologia, vol. 50, no. 1-2, pp. 123-130, 1998.

[29] H. Braat, E. C. de Jong, J. M. H. van den Brande et al., "Dichotomy between Lactobacillus rhamnosus and Klebsiella pneumoniae on dendritic cell phenotype and function," Journal of Molecular Medicine, vol. 82, no. 3, pp. 197-205, 2004.

[30] N. Baba, S. Samson, R. L. Bourdet-Sicard, M. Rubio, and M. Sarfati, "Commensal bacteria trigger a full dendritic cell maturation program that promotes the expansion of non-Tr1 
suppressor T cells," Journal of Leukocyte Biology, vol. 84, no. 2, pp. 468-476, 2008.

[31] S. Latvala, T. E. Pietilä, V. Veckman et al., "Potentially probiotic bacteria induce efficient maturation but differential cytokine production in human monocyte-derived dendritic cells," World Journal of Gastroenterology, vol. 14, no. 36, pp. 5570-5583, 2008.

[32] M. Mohamadzadeh, S. Olson, W. V. Kalina et al., "Lactobacilli active human dendritic cells that skew $\mathrm{T}$ cells toward $\mathrm{T}$ helper 1 polarization," Proceedings of the National Academy of Sciences of the United States of America, vol. 102, no. 8, pp. 2880-2885, 2005.

[33] M. Wiese, A. Eljaszewicz, M. Andryszczyk et al., "Immunomodulatory effects of Lactobacillus plantarum and helicobacter pylori CagA+ on the expression of selected superficial molecules on monocyte and lymphocyte and the synthesis of cytokines in whole blood culture," Journal of Physiology and Pharmacology, vol. 63, no. 3, pp. 217-224, 2012.

[34] M. B. Lutz and G. Schuler, "Immature, semi-mature and fully mature dendritic cells: which signals induce tolerance or immunity?" Trends in Immunology, vol. 23, no. 9, pp. 445-449, 2002.

[35] M. B. Lutz, "Therapeutic potential of semi-mature dendritic cells for tolerance induction," Frontiers in Immunology, vol. 3, no. 123, Article ID Article 123, 2012.

[36] A. M. Dudek, S. Martin, A. D. Garg, and P. Agostinis, "Immature, semi-mature, and fully mature dendritic cells: toward a DC-cancer cells interface that augments anticancer immunity," Frontiers in Immunology, vol. 4, article 438, 2013.

[37] F. Sallusto and A. Lanzavecchia, "The instructive role of dendritic cells on T-cell responses," Arthritis Research, vol. 4, supplement 3, pp. S127-S132, 2002.

[38] R. Rutkowski and T. Moniuszko, "Rola czasteczek kostymulujących B7.1 (CD80) i B7.2 (CD86) w patomechaniźmie odczynu zapalnego," Alergia Astma Immunologia, vol. 6, no. 2, pp. 87-94, 2001.

[39] N. S. Wilson, D. El-Sukkari, and J. A. Villadangos, "Dendritic cells constitutively present self antigens in their immature state in vivo and regulate antigen presentation by controlling the rates of MHC class II synthesis and endocytosis," Blood, vol. 103, no. 6, pp. 2187-2195, 2004.

[40] K. Kranzer, A. Eckhardt, M. Aigner et al., "Induction of maturation and cytokine release of human dendritic cells by Helicobacter pylori," Infection and Immunity, vol. 72, no. 8, pp. 4416-4423, 2004.

[41] M. Hubo, B. Trinschek, F. Kryczanowsky, A. Tuettenberg, K. Steinbrink, and H. Jonuleit, "Costimulatory molecules on immunogenic versus tolerogenic human dendritic cells," Frontiers in Immunology, vol. 4, article 82, 2013.

[42] B. M. Fu, X. S. He, S. Yu et al., "A tolerogenic semimature dendritic cells induce effector T-cell hyporesponsiveness by activation of antigen-specific CD4+CD25+ $\mathrm{T}$ regulatory cells that promotes skin allograft survival in mice," Cellular Immunology, vol. 261, no. 1, pp. 69-76, 2010.

[43] C. D. Gimmi, G. J. Freeman, J. G. Gribben, G. Gray, and L. M. Nadler, "Human T-cell clonal anergy is induced by antigen presentation in the absence of B7 costimulation," Proceedings of the National Academy of Sciences of the United States of America, vol. 90, no. 14, pp. 6586-6590, 1993.

[44] A. Landi, L. A. Babiuk, and S. van Drunen Littel-van den Hurk, "Dendritic cells matured by a prostaglandin E2-containing cocktail can produce high levels of IL-12p70 and are more mature and Thl-biased than dendritic cells treated with TNF$\alpha$ or LPS," Immunobiology, vol. 216, no. 6, pp. 649-662, 2011.
[45] C. Aerts-Toegaert, C. Heirman, S. Tuyaerts et al., "CD83 expression on dendritic cells and T cells: correlation with effective immune responses," European Journal of Immunology, vol. 37, no. 3, pp. 686-695, 2007.

[46] G. Weiss, S. Forster, A. Irving et al., "Helicobacter pylori VacA suppresses Lactobacillus acidophilus-induced interferon beta signaling in macrophages via alterations in the endocytic pathway," mBio, vol. 4, no. 3, Article ID e00609-12, 2013.

[47] S. A. Khader, J. E. Pearl, K. Sakamoto et al., "IL-23 compensates for the absence of IL-12p70 and is essential for the IL-17 response during tuberculosis but is dispensable for protection and antigen-specific IFN- $\gamma$ responses if IL-12p70 is available," Journal of Immunology, vol. 175, no. 2, pp. 788-795, 2005.

[48] M. M. Curtis and S. S. Way, "Interleukin-17 in host defence against bacterial, mycobacterial and fungal pathogens," Immunology, vol. 126, no. 2, pp. 177-185, 2009.

[49] H. H. Uhlig, B. S. McKenzie, S. Hue et al., "Differential activity of IL-12 and IL-23 in mucosal and systemic innate immune pathology," Immunity, vol. 25, no. 2, pp. 309-318, 2006.

[50] M. Menges, S. Rößner, C. Voigtländer et al., "Repetitive injections of dendritic cells matured with tumor necrosis factor $\alpha$ induce antigen-specific protection of mice from autoimmunity," The Journal of Experimental Medicine, vol. 195, no. 1, pp. 15-21, 2002.

[51] C. Voigtländer, S. Rössner, E. Cierpka et al., "Dendritic cells matured with TNF can be further activated in vitro and after subcutaneous injection in vivo which converts their tolerogenicity into immunogenicity," Journal of Immunotherapy, vol. 29, no. 4, pp. 407-415, 2006.

[52] M. L. Albert, M. Jegathesan, and R. B. Darnell, "Dendritic cell maturation is required for the cross-tolerization of CD8+ T cells," Nature Immunology, vol. 2, no. 11, pp. 1010-1017, 2001.

[53] A. Langenkamp, M. Messi, A. Lanzavecchia, and F. Sallusto, "Kinetics of dendritic cell activation: Impact on priming of TH1,TH2 and nonpolarized T cells," Nature Immunology, vol. 1, no. 4, pp. 311-316, 2000.

[54] D. J. MacEwan, "TNF receptor subtype signalling: differences and cellular consequences," Cellular Signalling, vol. 14, no. 6, pp. 477-492, 2002.

[55] A. Lubecka-Macura and M. Kohut, "TNF superfamily-mechanisms of action, biologic funtions and therapeutic possibilities," Przeglad Gastroenterologiczny, vol. 5, no. 6, pp. 303-309, 2010.

[56] J. U. Igietseme, G. A. Ananaba, J. Bolier et al., "Suppression of endogenous IL-10 gene expression in dendritic cells enhances antigen presentation for specific Th1 induction: Potential for cellular vaccine development," Journal of Immunology, vol. 164, no. 8, pp. 4212-4219, 2000.

[57] K. Sckäkel, "Dendritic cells-why can they help and hurt us," Experimental Dermatology, vol. 18, no. 3, pp. 264-273, 2009.

[58] R. Rad, L. Brenner, S. Bauer et al., "CD25+/Foxp3+ T cells regulate gastric inflammation and Helicobacter pylori colonization in vivo," Gastroenterology, vol. 131, no. 2, pp. 525-537, 2006. 


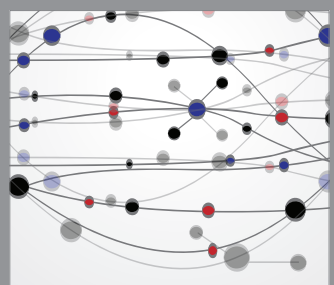

The Scientific World Journal
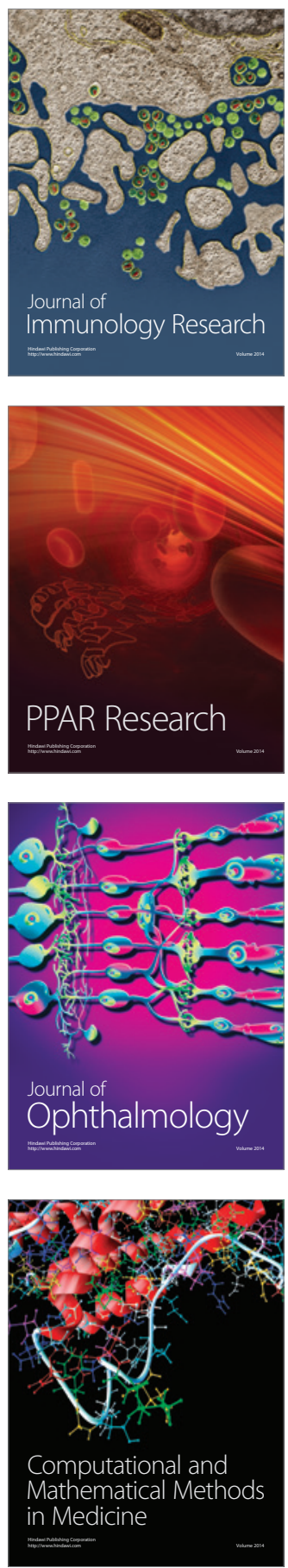

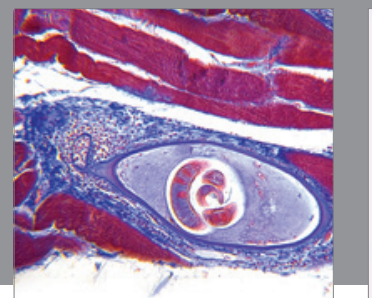

Gastroenterology

Research and Practice
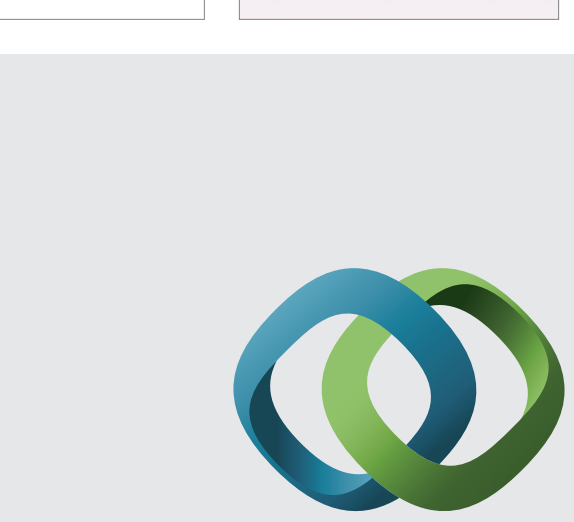

\section{Hindawi}

Submit your manuscripts at

http://www.hindawi.com
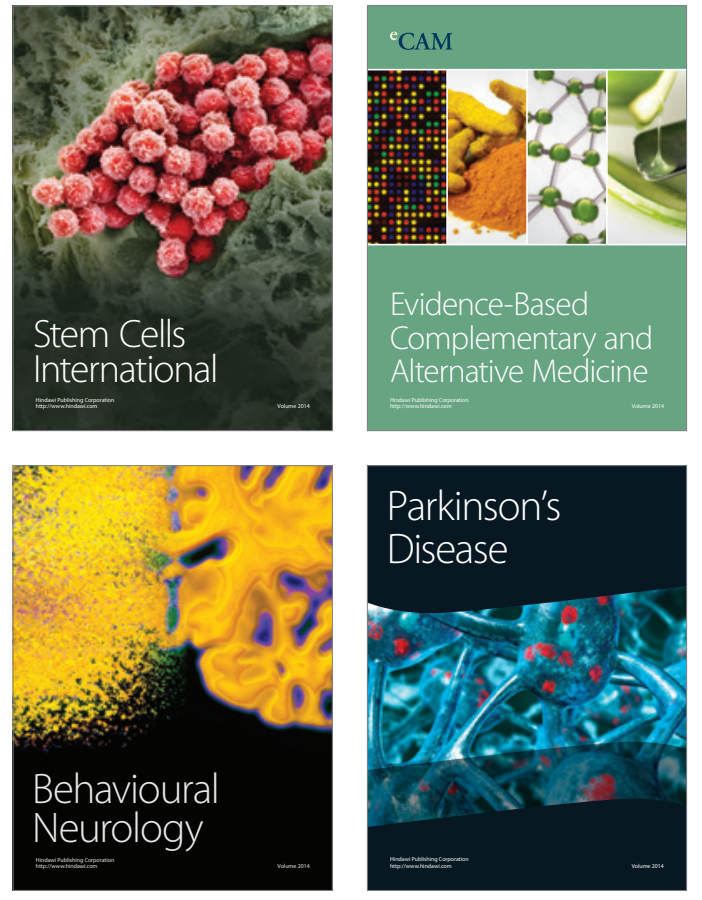
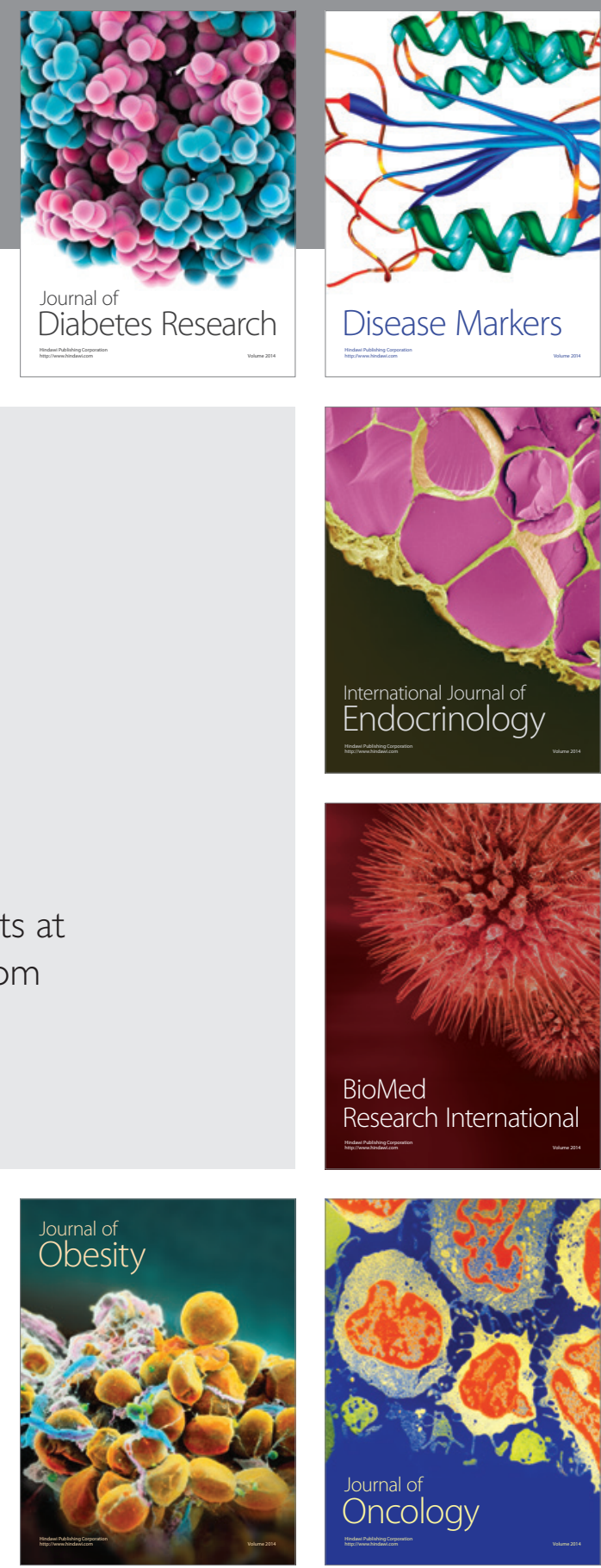

Disease Markers
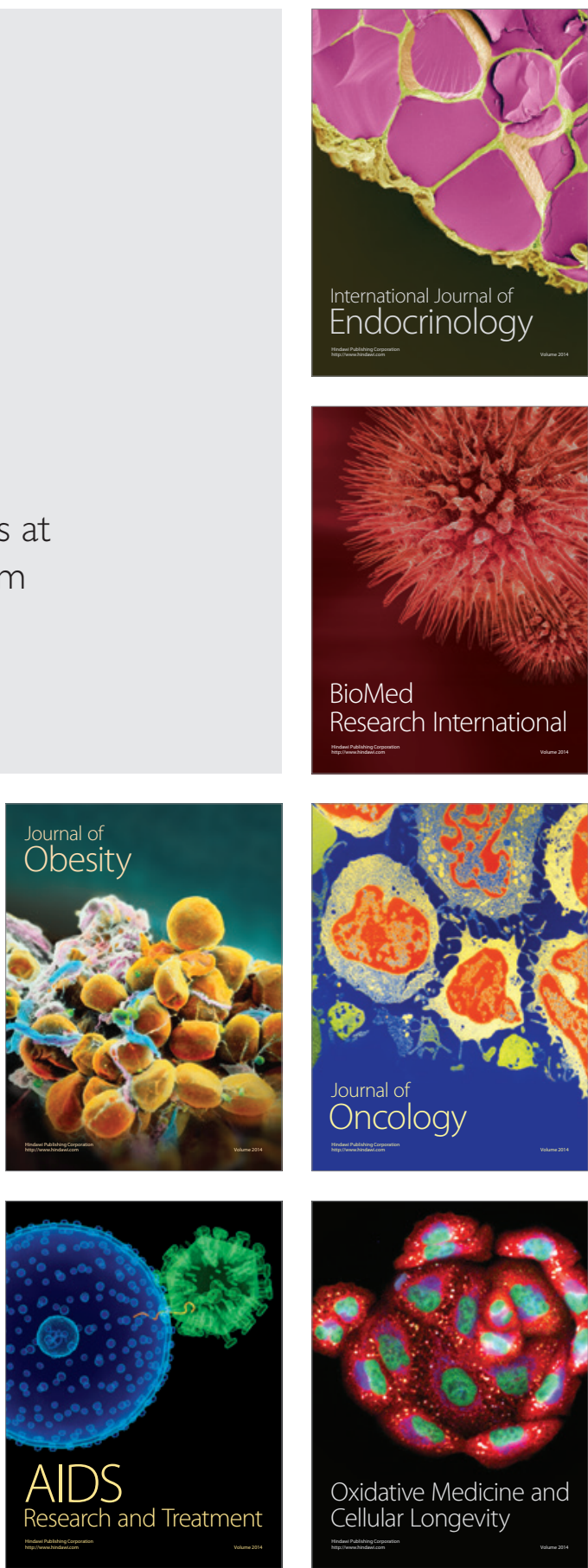